\title{
The role of fragmentation and landscape changes in the ecological release of common nest predators in the Neotropics
}

Loss of large mammalian carnivores may allow smaller mesopredators to become abundant and threaten other community members. There is considerable debate about mesopredator release and the role that other potential factors such as landscape variables and human alterations to land cover lead to increased mesopredator abundance. We used camera traps to detect four mesopredators (tayra, Eira barbara; white-nosed coati, Nasua narica; northern raccoon, Procyon lotor; and common opossum, Didelphis opossum) in a biological corridor in Costa Rica to estimate habitat covariates that influenced the species' detection and occurrence. We selected these mesopredators because as semi-arboreal species they might be common nest predators, posing a serious threat to resident and migratory songbirds. Pineapple production had a pronounced positive effect on the detectability of tayras, while forest cover had a negative effect on the detection of coatis. This suggests that abundance might be elevated due to the availability of agricultural food resources and foraging activities are concentrated in forest fragments and pineapple edge habitats. Raccoon and opossum models exhibited little influence on detection from habitat covariates. Occurrence models did not suggest any significant factors influencing site use by nest predators, revealing that all four species are habitat generalists adapted to co- existing in human altered landscapes. Furthermore, fragmentation and land cover changes may predispose nesting birds, herpetofauna, and small mammals to heightened predation risk by mesopredators in the Neotropics. 
1 The role of fragmentation and landscape changes in the ecological release of common nest

2 predators in the Neotropics

3 Michael V. Cove*

4 Department of Biology and Agriculture, University of Central Missouri, Warrensburg, MO

5 64093, USA

6 Current address: Department of Applied Ecology, North Carolina State University, Raleigh,

7 North Carolina, 27695, USA

8 R. Manuel Spínola

9 Instituto Internacional en Conservación y Manejo de Vida Silvestre, Universidad Nacional, 10 Apartado 1350-3000, Heredia, COSTA RICA

11 Victoria L. Jackson

12 Department of Biology and Agriculture, University of Central Missouri, Warrensburg, MO 13 64093, USA

14 Joel C. Saénz

15 Instituto Internacional en Conservación y Manejo de Vida Silvestre, Universidad Nacional, 16 Apartado 1350-3000, Heredia, COSTA RICA

17 *author to whom correspondence should be addressed (email: mvcove@ncsu.edu)

18 Keywords: camera traps, carnivores, coati, fragmentation, mesopredator release, Neotropics, nest

19 predators, pineapple production, raccoon, tayra 


\section{The role of fragmentation and landscape changes in the ecological release of common nest predators in the Neotropics}

Loss of large mammalian carnivores may allow smaller mesopredators to become abundant and

21 threaten other community members. Considerable debate exists about mesopredator release and

22 the role that other potential factors such as landscape variables and human alterations to land cover lead to increased mesopredator abundance. We used camera traps to detect four mesopredators (tayra, Eira barbara; white-nosed coati, Nasua narica; northern raccoon, Procyon lotor; and common opossum, Didelphis opossum) in a biological corridor in Costa Rica to estimate habitat covariates that influenced the species' detection and occurrence. We selected these mesopredators because as semi-arboreal species they might be common nest predators, posing a serious threat to resident and migratory songbirds. Pineapple production had a pronounced positive effect on the detectability of tayras, while forest cover had a negative effect on the detection of coatis. This result suggests that abundance might be elevated due to the availability of agricultural food resources and foraging activities are concentrated in forest fragments and pineapple-edge habitats. Raccoon and opossum models exhibited little influence on detection from habitat covariates. Occurrence models did not suggest any significant factors influencing site use by nest predators, revealing that all four species are habitat generalists adapted to co-existing in human altered landscapes. Furthermore, fragmentation and land cover changes may predispose nesting birds, herpetofauna, and small mammals to heightened predation

37 risk by mesopredators in the Neotropics.

\section{INTRODUCTION}

Large carnivores receive substantial attention from the scientific community due to their

40 charismatic status, their importance as keystone species in maintaining community structure, and

41 their susceptibility to extirpation from habitat loss (Morrison et al., 2007). Due to the loss of large 
42 carnivores from many systems, medium-sized carnivores and carnivorous marsupials

43 (collectively known as mesopredators) have recently gained more attention (Roemer et al., 2009)

44 because of their potential threat to migratory song birds (Crooks and Soulé, 1999; Donovan et al.,

45 1997; Elmhagen and Rushton, 2007; Garrott et al., 1993). The most commonly cited hypothesis

46 for the increased abundance of mesopredators is the Mesopredator Release Hypothesis (MRH -

47 Crooks and Soulé, 1999), but there is much debate that remains over the process of mesopredator

48 release (Cove et al., 2012a; Gerht and Clark, 2003; Elmhagen and Rushton, 2007). The MRH has

49 support within some families, most notably the Canidae, where larger canids drive the population

50 dynamics and habitat associations of smaller canids (Donadio and Buskirk, 2006; Gehrt and

51 Clark, 2003). However, interspecific killing and interference competition are less common among

52 different families (Donadio and Buskirk, 2006).

53 The top predators in Central America are jaguars (Panthera onca), pumas (Puma concolor),

54 and, coyotes (Canis latrans - Cove et al., 2012b; Wainwright, 2007). All three predators partake

55 in interspecific killing and may affect the distribution and habitat associations of smaller

56 mesopredators (Donadio and Buskirk, 2006; Palomares and Caro, 1999). The large cats are often

57 hunted due to cattle depredation and are rare. Coyotes are recent invaders and, because they

58 prefer disturbed open habitat, are seemingly rare in many intact forested areas. Mesopredators are

59 common in Central America which may result from the rarity of the top predators, thus,

60 supporting the MRH and a "top down" view of their release. Another plausible explanation is that

61 mesopredators are better adapted to coexisting with humans in disturbed habitats and, as

62 omnivores, are able to supplement their diets with agricultural resources via a "bottom up"

63 release (Elmhagen and Rushton, 2007; Garrott et al., 1993; Roemer et al., 2009).

64 Several studies in the United States attempted to model relative abundance of mesopredators

65 as functions of landscape and local habitat variables and predict predation risk for forest-nesting

66 birds (Crooks and Soulé, 1999; Dijack and Thompson, 2000; Donovan et al., 1997). These 
67 studies determined that mesopredator abundance, activities, and hence nest predation increased in

68 fragmented areas and within forest edge habitats, particularly surrounding agricultural lands.

69 However, no similar studies have examined mesopredator occurrence in Central America.

70 This study integrated data collected from camera traps and the occupancy modeling

71 framework developed by MacKenzie et al. $(2005,2006)$ in order to examine habitat associations

72 of four common mesopredators from three different families in a fragmented biological corridor

73 in Costa Rica. We selected tayra (Eira barbara), white-nosed coati (Nasua narica), northern

74 raccoon (Procyon lotor), and common opossum (Didelphis opossum) as the species of interest

75 because they are common, adapted to human presence, and are important nest predators due to

76 their semi-arboreal nature.

\section{2. METHODS}

78 Study site

79 The San Juan - La Selva Biological Corridor is the northernmost portion of the

80 Mesoamerican Biological Corridor in Costa Rica linking the Indio-Maíz Biological Reserve of

81 southeastern Nicaragua to the Braulio Carrillo National Park of central Costa Rica. At its northern

82 extent, the corridor also contains the proposed Maquenque National Park, which is the least

83 fragmented area in the region. Although deforestation of primary forest still occurs within the

84 corridor, government incentives (Forestry Law no. 7575) have encouraged reforestation and tree

85 plantations (Morse et al., 2009). Most of the land within the corridor is privately owned with

86 some reserves and lodges established to mitigate small scale agriculture, yet large scale pineapple

87 plantations and cattle operations continue to expand in the corridor and surrounding landscape,

88 particularly in the southern region (Fagen et al., 2013). We selected 16 survey sites to be

89 representative of the land cover in and around the corridor; selection was loosely based on

90 accessibility, forest patch size, and coverage along the entire corridor (Figure 1). All forest sites

91 were located on eco-lodge forest reserves, tree plantations, cattle ranches and agricultural 
92 plantations. In an effort to ensure independence among forest sites, we selected sites a minimum

93 of $2 \mathrm{~km}$ apart.

\section{Camera Trapping}

95 We surveyed fourteen forest sites over two field seasons (July-August 2009 and June-August

96 2010), while two additional sites were surveyed from October-November 2009. Information was

97 lost from one of these sites and was excluded from further analysis. To avoid the pitfalls of using

98 a single camera as a defined "site" representative of an entire forest (Efford and Dawson, 2012),

99 we decided to aggregate several traps in arrays at each site. Arrays consisted of a central camera

100 station and three additional camera stations surrounding the central station spaced at $>250 \mathrm{~m}$

101 apart, for a total of four cameras in the 2009 surveys. Cameras were arranged in an array of six

102 spaced $>250 \mathrm{~m}$ apart in the 2010 surveys. Previous research suggested that although this resulted

103 in variable trapnights among sites, there were no strong differences in detection as result of the

104 varying numbers of cameras (Cove et al., 2013). Each camera station consisted of a remotely

105 triggered infrared camera (Scout Guard SG550, HCO Outdoor Products, Norcross, GA, USA) or

106 a remotely triggered flash camera (Stealth Cam Sniper Pro Camera 57983, Stealth Cam, LLC,

107 Grand Prairie, TX, USA) secured to a sturdy tree $0.25-0.5 \mathrm{~m}$ off the ground. The camera was

108 directed at an opposing tree, 3-4 m away, baited with a secured can of sardines 1-1.5 m off the

109 ground. Although other camera trap studies set cameras along human trails and roads (Tobler et

110 al., 2008), we avoided areas of high human use due to threat of theft focusing on animal game

111 trails. Trail cameras were left at each site for 24-38 days and checked weekly for rebaiting and

112 battery changes.

113 All of our research was in accordance with the guidelines established by The American

114 Society of Mammalogists (Gannon et al., 2007). The camera trapping protocol was approved by 
115 the University of Central Missouri Institutional Animal Care and Use Committee (IACUC --

116 Permit No. 10-3202).

117 Habitat Variables and Analysis

118 Using ArcGIS 10.0 (ESRI, 380 New York Street, Redlands, CA 92373, USA), we overlaid 119 camera trap locations onto a digitized land use-land cover map. We created a 1-km radius buffer 120 at each site using a central point among the cameras to measure landscape covariates. Habitat

121 covariate selection was based on known ecology of the mesopredators and factors that might 122 affect their detection and occurrence (Gompper, 1995; Lotze and Anderson, 1979; McManus, 123 1974; Presley, 2000; Wainwright, 2007).

124 We measured the distance to the nearest village, creating an index of human presence and/or

125 disturbance. Forest cover is the percentage of buffer covered by primary and secondary forest and 126 tree plantations. Because pineapple plantations are prevalent in the region, we used a binomial 127 covariate to indicate this land use within each site buffer. The proposed Maquenque National 128 Park is also within the northern extent of the corridor and we used a similar binomial covariate to 129 denote sites as within or outside the proposed park boundaries. The final covariate was the total 130 number of patches within each site buffer, which is an index of habitat heterogeneity and habitat 131 fragmentation. We standardized all continuous covariates to $z$ scores for analysis, but performed 132 no other transformations (Long et al., 2011).

133 We combined all mesopredator photos from both field seasons to organize and manage binary 134 detection histories $(1=$ detected, $0=$ not detected $)$. We partitioned detection histories into five day 135 blocks for a maximum total of seven repeat surveys per species per site. We used the detection 136 histories and habitat covariates within a single-season occupancy model in program PRESENCE 1372.4 (Hines, 2009). Although the data were collected over two field seasons, we did not resample 138 any sites. This analysis refers to $\Psi$ as "site use" as opposed to "occurrence," so grouping of the 
139 field seasons does not violate any of the assumptions of the modeling process (MacKenzie et al., 140 2005).

141 Given our data, we developed six relatively simple a priori models for each species (Table 1),

142 including a global model, to estimate the influence of habitat covariates on detection probabilities

143 in the individual mesopredator detection models. Although detection probability is often

144 considered a nuisance parameter, there is an apparent relationship between detection probability

145 and local abundance because as local abundance increases the probability of detecting a species

146 will increase making it a parameter of interest in our study (O'Connell and Bailey, 2011). We did

147 not use a seasonal covariate because all surveys were conducted during the rainy season. We then

148 used the covariates that contained high model support and had strong effects on detection as a

149 constant covariate set in the subsequent occurrence models (Long et al., 2011). For the

150 occurrence models, we used seven a priori models (Table 2).

151 We determined the best approximating models based on the Akaike Information Criterion

152 corrected for small sample size $\left(\mathrm{AIC}_{\mathrm{c}}\right)$ and Akaike weights $\left(\omega_{i}\right)$. To evaluate model fit, we

153 performed 10,000 simulated parametric bootstraps for the global model (all covariates) to

154 determine if there was evidence of overdispersion (Burnham and Anderson, 2002). We

155 considered all models contained within the $90 \% \mathrm{CI}\left(\sum \omega_{i}>0.90\right)$ to have substantial support as the

156 top-ranking models (Burnham and Anderson, 2002).

157 3. RESULTS

158 From 2,286 camera trapnights, we obtained 23 independent photographs of tayras (10.06 159 photos/1000 trapnights), 33 photos of coati (14.44/1000 trapnights), 7 photos of raccoons

160 (3.06/1000 trapnights), and 23 photos of opossums (10.06/1000 trapnights). At least one nest 161 predator species was detected at every site, but only one site had detections of all four species. 
162 There was no evidence of overdispersion and we evaluated all models by their $\mathrm{AIC}_{\mathrm{c}}$ and their

163 Akaike weights.

164 Detection covariates affected each species differently (Table 3). Pineapple production had

165 high model support $\left(\sum \omega_{\mathrm{i}}=0.75\right)$ and a strong positive influence on detection probability for tayras

166 and was used as the constant detection covariate in subsequent occurrence models. Forest cover

167 had high model support $\left(\sum \omega_{\mathrm{i}}=0.67\right)$ and a negative influence on detection probabilities for coatis

168 and was used as the constant detection covariate in coati occurrence models. Raccoon and

169 opossum models contained minimal support for habitat covariates influencing detection and we

170 used a constant detection probability in the eventual occurrence models.

171 From the occurrence models, no covariates that we examined explained significant changes in

172 mesopredator occurrence at the study sites (Table 4). The top-ranking models for tayra and

173 raccoon suggested a negative influence of forest cover on both species' occurrence, but were

174 highly variable. The constant occurrence model was top-ranking for both coati and opossum.

\section{4. DISCUSSION}

$176 \quad$ No large cats were photographed during the surveys and only a single coyote was

177 photographed at one site (Cove et al., 2013). Local interviews and cattle depredation were

178 evidence that large cats occur in the corridor; however, the sparse records suggest rarity and

179 precluded the use of these presence/absence data as model covariates. Therefore, we were unable

180 to assess the impact and influence of these top predators on the four mesopredator species

181 through trophic interactions, but the observed detection rates in our surveys are higher than other

182 Neotropical studies with intact top predator communities (Tobler at al., 2008).

183 Landscape changes did affect detection parameters for the tayra and coati. Because camera

184 traps operate 24-hr per day, heightened detection corresponds with increased local abundance or

185 increased localized activity of mesopredators as influenced by landscape covariates. Pineapple 
production had a strong positive influence on the detection probability of the tayra. This is most

187 likely an effect of the additional food resources from pineapple production leading to higher local

188 tayra abundance in pineapple-forest edge habitats. The fruits not only provide direct food

189 resources to tayras but other food resources may be indirectly provided from pineapple pests

190 including small rodents, insects, and nesting birds (Presley, 2000). Furthermore this relationship

191 may also be a consequence of concentrated foraging activities within smaller forest patches that

192 commonly occur in the fragmented landscapes associated with pineapple plantations (Cove et al.,

193 2013). Pineapple production also had a positive influence on coati detection, but the effect was

194 less pronounced. Specifically, this suggests that coati abundance is also influenced by agricultural

195 food resources, similar to those associated with tayras, provided from pineapple production. The

196 effect was opposite for raccoons and opossums suggesting that pineapple production has a

197 negative but weak influence on their detection. This result may be an artifact of limited raccoon

198 detections or avoidance of areas of high use by tayras and coatis.

199 Forest cover had a negative effect on detection probability of coatis. Such an effect suggests

200 that coatis, which occur in large groups, concentrate their foraging activities in small forest

201 patches, making them more easily detectable. This relationship was similar for the detection of

202 tayras and raccoons in the study area. The consequence of such concentrated foraging activities in

203 small forest patches and forest edges has also been shown to be responsible for exposing nesting

204 song birds to increased predation risk (Cove et al., 2012c; Dijack and Thompson, 2000; Donovan

205 et al., 1997). However, none of the habitat covariates examined in this analysis were significant

206 predictors of mesopredator occurrence. Although the coefficients for habitat generally agreed

207 with a priori expectations that increased forest cover would have a negative but variable

208 influence on mesopredator occurrence, lack of significant covariate effects suggests that the

209 broad range of habitats used by these predators could have drastic consequences for nesting song

210 birds, small mammals, and herpetofauna if fragmentation and forest loss continues. 
Although low detections of large predators made it difficult to provide direct support for the

$212 \mathrm{MRH}$, the rarity of these species most likely plays a role in the distribution and habitat use by

213 mesopredators. More importantly, the compounding factors of increasing human presence,

214 decreasing forest cover, and increasing pineapple production play an important role in

215 mesopredator release and potentially heightened local abundance. Further sampling of

216 mesopredator communities, as well as large predator-specific surveys and avian point count

217 surveys, will elucidate trophic interactions and the risk of predation to migratory and resident

218 song birds.

219 Acknowledgements: We thank all the field assistants and lodges that helped with logistics for

220 this research. Special thanks to Daniel Corrales and Panthera - Costa Rica, Finca Pangola, Selva

221 Verde Lodge, and Laguna Lagarto Lodge for their assistance and continued support.

\section{REFERENCES}

223

224

225

226

227

228

229

230

231

232

233

234

235

236

237
Burnham, K. P., and Anderson D. R. 2002. Model selection and multimodel inference: a practical information-theoretic approach. Second edition. Springer-Verlag, New York, New York.

Cove, M. V., Jones, B. M., Bossert, A. J., Clever Jr., D. R., Dunwoody, R. K., White, B. C. and Jackson, V. L. 2012a. Use of camera traps to examine the mesopredator release hypothesis in a fragmented Midwestern landscape. American Midland Naturalist 168: 456-465.

Cove, M. V., Pardo, L., Spínola, R. M., Jackson, V. L., and Saenz, J. C. 2012b. Coyote Canis latrans (Carnivora: Canidae) range extension in northeastern Costa Rica: possible explanations and consequences. Latin American Journal of Conservation 3: 82-86.

Cove, M. V., L. M. Niva, and V. L. Jackson. 2012c. Use of probability of detection when conducting analyses of surveys of mesopredators: A Case Study from the Ozark Highlands of Missouri. The Southwestern Naturalist 57: 258-262.

Cove, M. V., R. M. Spínola, V. L. Jackson, J. C. Saenz, and O. Chassot. 2013. Integrating occupancy modeling and camera-trap data to estimate medium and large mammal detection and richness in a Central American biological corridor. Tropical Conservation Science 6: 781795. 
Crooks, K. R., and Soulé, M. E. 1999. Mesopredator release and avifaunal extinctions in a fragmented system. Nature 400:563-566.

Dijack, W. D., and Thompson III, F. R. 2000. Landscape and edge effects on the distribution of mammalian predators in Missouri. Journal of Wildlife Management 64: 209-216.

Donadio, E., and Buskirk, S. W. 2006. Diet, morphology, and interspecific killing in Carnivora. American Naturalist 167:524-536.

Donovan, T. M., Jones, P. W., Annand, E. M. and Thompson III, F. R. 1997. Variation in localscale edge effects: Mechanisms and landscape context. Ecology 78:2064-2075.

Efford, M. G., and Dawson, D. K. 2012. Occupancy in continuous habitat. Ecosphere 3:32.

Elmhagen, B., and Rushton, S. P. 2007. Trophic control of mesopredators in the terrestrial ecosystems: top-down or bottom-up? Ecology Letters 10:197-206.

Fagen, M. E., DeFries, R. S., Sensie, S. E., Arroyo, J. P., Walker, W., Soto, C., Chazdon, R. L. and Sanchum, A. 2013. Land cover dynamics following a deforestation ban in northern Costa Rica. Environmental Research Letters 8:034017.

Gannon, W. L., Sikes, R. S. and the Animal Care and Use Committee of the American Society of Mammalogists. 2007. Guidelines of the American Society of Mammalogists for the use of wild animals in research. Journal of Mammalogy 88:809-823.

Garrott, R. A., White, P. J. and Vanderbilt White, C. A. 1993. Overabundance: an issue for conservation biologists? Conservation Biology 7:946-949.

Gehrt, S. D., and Clark, W. R. 2003. Raccoons, coyotes, and reflections on the mesopredator release hypothesis. Wildlife Society Bulletin 31:836-842.

Gompper, M. E. 1995. Nasua narica. Mammalian Species 487:1-10.

Hines, J. E. 2009. Presence 2.4 - software to estimate patch occupancy and related parameters: USGS-PWRC. http://www.mbr-pwrc.usgs.gov/software/presence.html

Long, R. A., Donovan, T. M., MacKay, P., Zielinski, W. J., and Buzas, J. S. 2011. Predicting carnivore occurrence with noninvasive surveys and occupancy modeling. Landscape Ecology 26:327-340.

Lotze, J.-H. and Anderson, S. 1979. Procyon lotor. Mammalian Species 119:1-8.

MacKenzie, D. I., Nichols, J. D., Sutton, N., Kawanishi, K., and Bailey, L. L. 2005. Improving inferences in population studies of rare species that are detected imperfectly. Ecology 86:1101-1113.

MacKenzie, D. I., Nichols, J. D., Royle, J. A., Pollock, K. H., Bailey, L. L. and Hines, J. E. 2006. Occupancy estimation and modeling. Academic Press, Burlington, Massachusetts. 
271 McManus, J. J. 1974. Didelphis Virginiana. Mammalian Species 40:1-6.

272 Morrison, J. C., Sechrest, W., Dinerstein, E., Wilcove, D. S., and Lamoreux, J. F. 2007.

273 Persistence of large mammal faunas as indicators of global human impacts. Journal of

274 Mammalogy 88:1363-1380.

275 Morse, W. C., Schedlbauer, J. L., Sensie, S. E., Finegan, B., Harvey, C. A., Hollenhorst, S. J.,

276 Kavanagh, K. L., Stoian, D. and Wulfhurst, J. D. 2009. Consequences of environmental

277 service payments for forest retention and recruitment in a Costa Rican biological corridor.

278 Ecology and Society 14:23.

279 O'Connell, A. F., and Bailey, L. L. 2011. Inference for occupancy and occupancy dynamics.

280 Pages 191-207 in O'Connell, A. F., J. D. Nichols, and K. U. Karanth, editors. Camera traps in 281 animal ecology: methods and analyses. Springer, New York, New York.

282

283

284

285

286

287

288

289

290

291

292

293

O'Connell, A. F., Nichols, J. D., and Karanth, K. U. 2011. Camera traps in animal ecology: methods and analyses. Springer, New York, New York.

Palomares, F., and Caro, T. M. 1999. Interspecific killing among mammalian carnivores. American Naturalist 153:492-508.

Presley, S. J. 2000. Eira barbara. Mammalian Species 636: 1-6.

Roemer, G. W., Gompper, M. E. and Van Valkenburgh, B. 2009. The ecological role of the mammalian mesocarnivore. Bioscience 59:165-173.

Tobler, M. W., Carrillo-Percastegui, S. E., Leite Pitman, R., Mares, R., and Powell, G. 2008. An evaluation of camera traps for inventorying large and medium sized terrestrial rainforest mammals. Animal Conservation 11:169-178.

Wainwright, M. 2007. The mammals of Costa Rica: A natural history and field guide. Cornell University Press, Ithaca.

294 Caption for Figure:

295

296

297

298

299

300

Figure 1: Map of camera trap survey locations and the forest cover (including primary, secondary, and tree plantations) within the San Juan - La Selva Biological Corridor and its relative location in Costa Rica. Sites located outside of the corridor were located in isolated forest fragments except the furthest south, which was located in Braulio Carillo National Park. The inset diagram shows the relationship that we examined of the effects of land cover change on nest predators and the apparent relationships to large predators and Neotropical birds. 
302 Supplemental data includes the camera detection histories for all four species as well as site303 specific habitat data from the sites included in the analyses. 


\section{Figure 1}

\section{Map of study area}
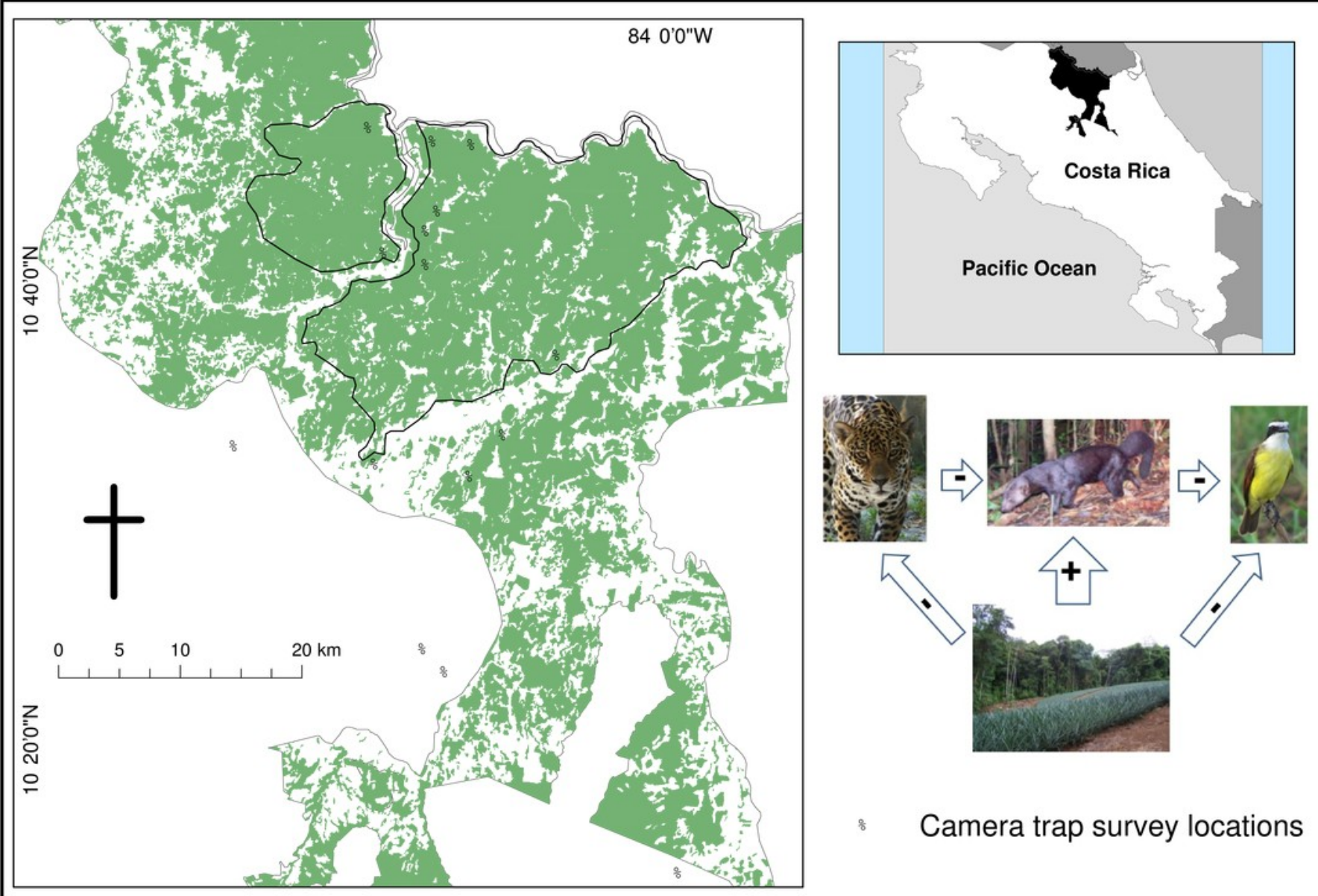

: Camera trap survey locations 


\section{Table 1 (on next page)}

A priori hypotheses regarding detection 
Table 1. Descriptions and expected direction of a priori detection $(p)$ models for mesopredators from camera trap surveys in the San Juan - La Selva Biological Corridor, Costa Rica, 2009-2010.

\begin{tabular}{|c|c|c|c|}
\hline Hypothesis $\stackrel{\circ}{=}$ & Model & Model Structure & Expected Result \\
\hline No habitat covariateşaffect detection & $p()$. & $\beta_{0}$ & - \\
\hline $\begin{array}{l}\text { Mesopredator abundance and foraging increase in close proximity to } \\
\text { villages so as distance to village increases detection decreases }\end{array}$ & $p$ (dist) & $\beta_{0}+\beta_{1}($ dist $)$ & $\beta_{1}<0$ \\
\hline $\begin{array}{l}\text { Habitat heterogeneit and fragmentation increase forest edge and } \\
\text { lead to higher foraging and detection }\end{array}$ & $p(\operatorname{tnp})$ & $\beta_{0}+\beta_{1}(\operatorname{tn} p)$ & $\beta_{1}>0$ \\
\hline $\begin{array}{l}\text { Pineapple production provides food resources and increases } \\
\text { abundance and detection }\end{array}$ & $p($ pina $)$ & $\beta_{0}+\beta_{1}($ pina $)$ & $\beta_{1}>0$ \\
\hline $\begin{array}{l}\text { Increasing forest cor will have a negative effect on detection } \\
\text { because activities v l be less concentrated }\end{array}$ & $p$ (for) & $\beta_{0}+\beta_{1}$ (for) & $\beta_{1}<0$ \\
\hline $\begin{array}{l}\text { Distance to village, habitat heterogeneity, pineapple production, and } \\
\text { forest cover all affect detection }\end{array}$ & $p$ (global) & $\begin{array}{l}\beta_{0}+\beta_{1}(\text { dist })+\beta_{2}(\text { tnp }) \\
+\beta_{3} \text { (pina) }+\beta_{4} \text { (for) } \\
\end{array}$ & $\begin{array}{l}\beta_{1}<0, \beta_{2}>0 \\
\beta_{3}>0, \beta_{4}<0\end{array}$ \\
\hline
\end{tabular}




\section{Table 2 (on next page)}

A priori Hypothese regarding occurrence 
Table 2. Descriptions and expected direction of a priori occurrence $(\Psi)$ models for mesopredators from camera trap surveys in the San Juan - La Selva Biological Corridor, Costa Rica, 2009-2010.

\begin{tabular}{|c|c|c|c|}
\hline Hypothesis $\quad \frac{+}{-\frac{0}{\frac{6}{2}}}$ & Model & Model Structure & $\begin{array}{c}\text { Expected } \\
\text { Result }\end{array}$ \\
\hline No habitat effects on $\underset{\subsetneq}{\infty}$ ccurrence & $\Psi()$. & $\beta_{0}$ & - \\
\hline Negative effect on oscurrence within Maquenque National & & & \\
\hline Park $\quad$ g) & $\Psi(\mathrm{Maq})$ & $\beta_{0}+\beta_{1}(\mathrm{Maq})$ & $\beta_{1}<0$ \\
\hline Negative effect on oscurrence as distance to village increases & $\Psi($ dist $)$ & $\beta_{0}+\beta_{1}($ dist $)$ & $\beta_{1}<0$ \\
\hline $\begin{array}{l}\text { Positive effect on occurrence as habitat heterogeneity } \\
\text { increases }\end{array}$ & $\Psi(\operatorname{tnp})$ & $\beta_{0}+\beta_{1}(\operatorname{tnp})$ & $\beta_{1}>0$ \\
\hline $\begin{array}{l}\text { Negative effect on gcurrence as forest cover increases and } \\
\text { provides habitat for grger predators }\end{array}$ & $\Psi($ for $)$ & $\beta_{0}+\beta_{1}($ for $)$ & $\beta_{1}<0$ \\
\hline $\begin{array}{l}\text { Positive effect on Q Qurrence with pineapple production } \\
\text { present }\end{array}$ & $\Psi($ pina $)$ & $\beta_{0}+\beta_{1}($ pina $)$ & $\beta_{1}>0$ \\
\hline $\begin{array}{l}\text { Maquenque National Park, distance to village, habitat } \\
\text { heterogeneity, forest cover, and pineapple production all } \\
\text { affect occurrence }\end{array}$ & $\Psi($ global $)$ & $\begin{array}{c}\beta_{0}+\beta_{1}(\mathrm{Maq})+\beta_{2}(\text { dist }) \\
+\beta_{3}(\operatorname{tnp})+\beta_{4}(\text { for })+ \\
\beta_{5}(\text { pina }) \\
\end{array}$ & $\begin{array}{c}\beta_{1}<0, \beta_{2}<0 \\
\beta_{3}>0, \beta_{4}>0 \\
\beta_{5}>0 \\
\end{array}$ \\
\hline
\end{tabular}




\section{Table 3 (on next page)}

Results for detection 
Table 3. Selected top models and untransformed coefficients of habitat variable effects on detection probability ( $p$ ) for mesopredators from camera trap surveys in the San Juan - La Selva Biological Corridor, Costa Rica, 2009-2010.

\begin{tabular}{|c|c|c|c|c|c|c|c|c|}
\hline \multirow[b]{2}{*}{$\begin{array}{l}\text { Species } \\
\text { Model } \\
\end{array}$} & \multirow[b]{2}{*}{$\stackrel{+\frac{\varrho}{\tau}}{=} \Delta_{i}$} & \multirow[b]{2}{*}{$\omega_{i}$} & \multirow[b]{2}{*}{$K$} & \multicolumn{5}{|c|}{ Untransformed coefficients of covariates (SE) } \\
\hline & & & & Intercept & Pineapple & $\begin{array}{c}\text { Total number } \\
\text { of patches }\end{array}$ & Distance & Forest \\
\hline Tayra & 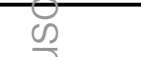 & & & & & & & \\
\hline$p($ pina $)$ & $\supseteq 0.00$ & 0.611 & 3 & $-2.695(0.662)$ & $2.211(0.743)$ & - & - & - \\
\hline$p$ (global) & তี 2.97 & 0.138 & 6 & $-3.646(0.837)$ & $2.626(0.918)$ & $1.016(0.423)$ & $0.659(0.338)$ & $-0.303(0.502)$ \\
\hline$p(\operatorname{tnp})$ & $\geq 3.38$ & 0.113 & 3 & $-1.311(0.465)$ & - & $0.701(0.368)$ & - & - \\
\hline$p()$. & $\subseteq 3.89$ & 0.087 & 2 & $-0.807(0.355)$ & - & - & - & - \\
\hline Coati & $\overline{3}$ & & & & & & & \\
\hline$p$ (for) & 0.00 & 0.667 & 3 & $-0.214(0.291)$ & - & - & - & $-0.784(0.330)$ \\
\hline$p()$. & ¿2.93 & 0.154 & 2 & $-0.329(0.279)$ & - & - & - & - \\
\hline$p($ pina $)$ & $\simeq_{4.26}$ & 0.079 & 3 & $-0.705(0.409)$ & $0.763(0.567)$ & - & - & - \\
\hline$p($ dist $)$ & 34.65 & 0.065 & 3 & $-0.313(0.279)$ & - & - & $-0.322(0.271)$ & - \\
\hline \multicolumn{9}{|l|}{ Raccoon } \\
\hline$p()$. & 0.00 & 0.383 & 2 & $-1.157(0.599)$ & - & - & - & - \\
\hline$p(\operatorname{tnp})$ & (d) 1.15 & 0.216 & 3 & $-1.793(0.805)$ & - & $0.691(0.471)$ & - & - \\
\hline$p($ dist $)$ & 2.15 & 0.131 & 3 & $-1.035(0.570)$ & - & - & $0.819(0.747)$ & - \\
\hline$p($ pina $)$ & 2.46 & 0.112 & 3 & $-0.444(0.915)$ & $-1.007(1.144)$ & - & - & - \\
\hline$p$ (for) & 2.55 & 0.107 & 3 & $-2.494(1.176)$ & - & - & - & $-0.780(0.637)$ \\
\hline \multicolumn{9}{|l|}{ Opossum } \\
\hline$p()$. & 0.00 & 0.545 & 2 & $-0.621(0.323)$ & - & - & - & - \\
\hline$p$ (pina) & 3.08 & 0.117 & 3 & $-0.543(0.402)$ & $-0.207(0.660)$ & - & - & - \\
\hline$p$ (for) & 3.12 & 0.115 & 3 & $-0.612(0.324)$ & - & - & - & $0.080(0.339)$ \\
\hline$p(\operatorname{tnp})$ & 3.17 & 0.112 & 3 & $-0.628(0.335)$ & - & $-0.025(0.291)$ & - & - \\
\hline$p($ dist $)$ & 3.17 & 0.112 & 3 & $-0.621(0.323)$ & - & - & $0.039(0.417)$ & - \\
\hline
\end{tabular}

Models presented make up the $95 \%$ confidence set, where $\Delta_{\mathrm{i}}$ is $\mathrm{AIC}_{\mathrm{c}}$ difference, $\omega_{i}$ is the Akaike weight, and $\mathrm{K}$ is the number of model parameters. Model covariates were used as a constant detection set for occurrence models for species that did not exhibit the $\mathrm{p}($.$) as the top ranking model$ (tayra and coati).

Covariates: pina is the binomial term to identify large-scale pineapple production within the site buffer; tnp is the total number of patches within the buffer; dist is the linear distance $(\mathrm{km})$ to the nearest village; for is the total percent of forest cover (primary, secondary, and tree plantations) within the site buffer. 


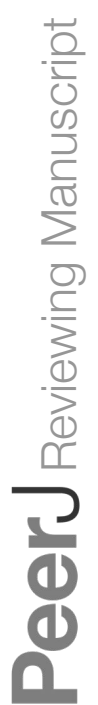

PeerJ reviewing PDF | (v2014:03:1882:1:1:NEW 10 Jun 2014) 


\section{Table 4 (on next page)}

\section{Results for occurrence}


Table 4. Selected top models and untransformed coefficients of habitat variable effects on occurrence models $(\Psi)$ for mesopredators from camera trap surveys in the San Juan - La Selva Biological Corridor, Costa Rica, 2009-2010.

\begin{tabular}{|c|c|c|c|c|c|c|c|c|c|}
\hline \multirow[b]{2}{*}{$\begin{array}{r}\text { Species } \\
\text { Model } \\
\end{array}$} & \multirow[b]{2}{*}{$\Delta_{i}$} & \multirow{2}{*}{$\begin{array}{l}\frac{}{\bar{v}} \\
\frac{\mathscr{D}}{\partial} \\
\stackrel{c}{c} \omega_{i} \\
\end{array}$} & \multicolumn{7}{|c|}{ Untransformed coefficients of covariates (SE) } \\
\hline & & & $K$ & Intercept & Forest & Maquenque & $\begin{array}{c}\text { Total number of } \\
\text { patches }\end{array}$ & Pineapples & Distance \\
\hline Tayra & & $\sum$ & & & & & & & \\
\hline$\Psi($ for $)$ & 0.00 & 0.432 & 4 & $1.568(2.074)$ & $-2.874(2.709)$ & - & - & - & - \\
\hline$\Psi(\mathrm{Maq})$ & 1.96 & G62 & 4 & $1.820(1.333)$ & - & $-2.875(1.849)$ & - & - & - \\
\hline$\Psi(\operatorname{tnp})$ & 2.14 & (0)148 & 4 & $1.485(1.365)$ & - & - & $1.507(1.478)$ & - & - \\
\hline$\Psi($ pina $)$ & 2.83 & (a) 105 & 4 & $-0.464(1.393)$ & - & - & - & $2.313(1.955)$ & - \\
\hline$\Psi($ dist $)$ & 3.35 & 0,081 & 4 & $1.905(1.651)$ & - & - & - & - & $0.393(1.144)$ \\
\hline \multicolumn{10}{|l|}{ Coati } \\
\hline$\Psi()$. & 0.00 & (1) 487 & 3 & $0.532(0.569)$ & - & - & - & - & - \\
\hline$\Psi($ for $)$ & 2.63 & (1) 131 & 4 & $0.679(0.676)$ & $-0.678(0.673)$ & - & - & - & - \\
\hline$\Psi(\mathrm{Maq})$ & 2.77 & A. 122 & 4 & $0.055(0.727)$ & - & $1.247(1.307)$ & - & - & - \\
\hline$\Psi(\operatorname{tnp})$ & 2.95 & 0.111 & 4 & $0.528(0.579)$ & - & - & $0.593(0.667)$ & - & - \\
\hline$\Psi($ dist $)$ & 3.74 & 0.075 & 4 & $0.544(0.577)$ & - & - & - & - & $0.162(0.576)$ \\
\hline
\end{tabular}

Models presented make up the $90 \%$ confidence set, where $\Delta_{\mathrm{i}}$ is $\mathrm{AIC}_{\mathrm{c}}$ difference, $\omega_{i}$ is the Akaike weight, and $\mathrm{K}$ is the number of model parameters. Coefficients are in logit space and relate to standardized covariates.

Covariates: for is the total percent of forest cover (primary, secondary, and tree plantations) within the site buffer; Maq is the binomial term for sites within the proposed Maquenque National Park; tnp is the total number of patches within the buffer; pina is the binomial term to identify large-scale pineapple production within the site buffer; dist is the linear distance $(\mathrm{km})$ to the nearest village. 
Table 4 continued.

\begin{tabular}{|c|c|c|c|c|c|c|c|c|c|}
\hline \multirow[b]{2}{*}{$\begin{array}{r}\text { Species } \\
\text { Model } \\
\end{array}$} & \multirow[b]{2}{*}{$\Delta_{i}$} & \multirow[b]{2}{*}{$\omega_{i}$} & \multicolumn{7}{|c|}{ Untransformed coefficients of covariates (SE) } \\
\hline & & & $K$ & Intercept & Forest & Maquenque & $\begin{array}{c}\text { Total number of } \\
\text { patches }\end{array}$ & Pineapples & $\begin{array}{c}\text { Distan } \\
\text { ce }\end{array}$ \\
\hline Raccoon & & $\therefore$ & & & & & & & \\
\hline$\Psi($ for $)$ & $\begin{array}{c}0.0 \\
0 \\
2.5\end{array}$ & 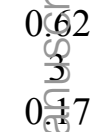 & 3 & $-1.940(1.218)$ & $-2.052(1.203)$ & - & - & - & - \\
\hline$\Psi()$. & $\begin{array}{c}2 \\
4.6\end{array}$ & $\frac{7}{0.06}$ & 2 & $-1.129(0.729)$ & - & - & - & - & - \\
\hline$\Psi($ pina $)$ & $\begin{array}{c}4 \\
4.6\end{array}$ & 0 & 3 & $-1.845(1.115))$ & - & - & - & $1.444(1.458)$ & - \\
\hline$\Psi(\operatorname{tnp})$ & 9 & 或 & 3 & $-1.270(0.789)$ & - & - & $0.699(0.718)$ & - & - \\
\hline Opossum & 0.0 & $\frac{\simeq}{0.45}$ & & & & & & & \\
\hline$\Psi()$. & 0 & (6) 5 & 2 & $0.276(0.569)$ & - & - & - & - & - \\
\hline$\Psi(\operatorname{tnp})$ & $\begin{array}{c}2.11 \\
3.0\end{array}$ & 0.09 & 3 & $0.287(0.594)$ & - & - & $-0.600(0.604)$ & - & - \\
\hline$\Psi($ for $)$ & $\begin{array}{c}7 \\
3.0\end{array}$ & $\begin{array}{c}8 \\
0.09\end{array}$ & 3 & $0.278(0.573)$ & $-0.198(0.600)$ & - & - & - & - \\
\hline$\Psi(\mathrm{Maq})$ & $\begin{array}{c}8 \\
3.1\end{array}$ & $\begin{array}{c}8 \\
0.09\end{array}$ & 3 & $0.118(0.757)$ & - & $0.349(1.133)$ & - & - & - \\
\hline$\Psi($ pina $)$ & 3 & 6 & 3 & $0.381(0.743)$ & - & - & - & $-0.258(1.138)$ & - \\
\hline
\end{tabular}

Models presented make up the $90 \%$ confidence set, where $\Delta_{\mathrm{i}}$ is $\mathrm{AIC}_{\mathrm{c}}$ difference, $\omega_{i}$ is the Akaike weight, and $\mathrm{K}$ is the number of model parameters. Coefficients are in logit space and relate to standardized covariates.

Covariates: for is the total percent of forest cover (primary, secondary, and tree plantations) within the site buffer; Maq is the binomial term for sites within the proposed Maquenque National Park; tnp is the total number of patches within the buffer; pina is the binomial term to identify large-scale pineapple production within the site buffer; dist is the linear distance (km) to the nearest village. 


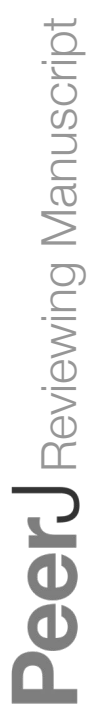

PeerJ reviewing PDF | (v2014:03:1882:1:1:NEW 10 Jun 2014) 